\title{
Kendali Pencahayaan Ruangan Berdasarkan Adanya Orang Di Dalam Ruangan dan Pemantauan Jumlah Orang
}

\author{
Joni Fat ${ }^{1}$, Endah Setyaningsih ${ }^{1}$, Henry Candra ${ }^{2}$
}

\begin{abstract}
Energy saving in a room is one way to support government programs. Examples and implementation of energy savings should be instilled in someone early. Through the design of this system students are shown one way to save energy, namely through space lighting control. The system made consists of hardware and software. The system hardware will use a processor in the form of a microprocessor and infrared light sensor installed on the door. In addition, it will also be connected to a server on the Internet so that the system can also be monitored through a web application. Display using a website and calculation results can be printed on a paper. This system design was applied to one of the classrooms, namely as a lighting level controller in the fo

rm of igniting and on-off classroom lights automatically when there is and no students. Light control will be designed using a relay. This system is expected to not only have a real effect in reducing the use of electric power in the room that is applied, it can also be a tool to demonstrate the application of technology to teachers and students.
\end{abstract}

KEYWORD: Lighting, microprocessor, infrared, automatic, energy saving.

\begin{abstract}
ABSTRAK: Melakukan penghematan energi pada suatu ruangan, merupakan salah satu cara dalam mendukung program pemerintah. Contoh dan pelaksanaan penghematan energi sebaiknya ditanamkan kepada seseorang sejak dini. Melalui perancangan sistem ini siswa ditunjukkan salah satu cara hemat energi, yaitu melalui pengendalian pencahayaan ruangaan. Sistem yang dibuat terdiri dari hardware dan software. Hardware sistem akan menggunakan pemroses berupa mikroprosesor dan sensor cahaya infra merah yang dipasang di pintu. Selain itu, juga akan terhubung dengan server di Internet sehingga sistem juga dapat dimonitor melalui aplikasi web. Tampilan menggunakan sebuah website dan hasil penghitungan bisa dicetak pada sebuah kertas. Rancangan sistem ini diaplikasikan pada salah satu ruang kelas, yaitu sebagai pengendali tingkat pencahayaan berupa penyalaan dan mematikan (on-off) lampu ruang kelas secara otomatis pada saat ada dan tidak ada siswa. Kontrol lampu akan dirancang menggunakan sebuah relay. Sistem ini diharapkan selain dapat berefek nyata dalam penurunan pemakaian daya listrik dalam ruangan yang diaplikasikan, juga dapat menjadi alat untuk mendemonstrasikan aplikasi teknologi bagi para Guru dan siswa.
\end{abstract}

Kata kunci: Pencahayaan, mikroprosesor, inframerah, otomatis, penghematan energi.

\section{PENDAHULUAN}

$\mathrm{M}_{\mathrm{c}}$ elakukan penghematan energi pada suatu ruangan, merupakan salah satu cara dalam mendukung program pemerintah. Contoh dan pelaksanaan penghematan energi sebaiknya ditanamkan kepada seseorang sejak dini. Cara yang paling sederhana adalah siswa diminta untuk mematikan peralatan listrik seperti lampu dan pendingin ruangan yang ada di ruang kelas jika ruang tersebut tidak digunakan. Cara lain dapat berupa otomatisasi untuk mematikan dan menghidupkan peralatan listrik tersebut. Melalui perancangan sistem ini siswa ditunjukkan salah satu cara hemat energi, yaitu melalui pengendalian pencahayaan ruangaan, yaitu on-off lampu jika ada atau tidak ada orang dalam ruangan. Perancangan sistem ini juga dapat digunakan untuk menghitung siswa yang keluar atau masuk dari ruang. Penghitungan siswa akan menggunakans sebuah modul sensor inframerah yang terdiri dari komponen LED inframerah dan LED penerima inframerah, ketika bagian penghitung masuk aktif maka jumlah siswa akan bertambah, ketika penghitung keluar aktif maka jumlah siswa akan berkurang sesuai dengan jumlah orang yang masuk dan keluar. Pintu akan dipasang sebuah sensor inframerah, untuk menghitung pengunjung.

Tampilan menggunakan sebuah website dan hasil penghitungan bisa dicetak pada sebuah kertas. Kontrol lampu akan dirancang menggunakan sebuah relay. Sementara itu tujuan rancangan ini adalah untuk menghasilkan sistem yang dapat melakukan penghitunga jumlah siswa dengan tampilan pada sebuah website. Selain itu, perancangan sistem dapat memberikan kendali pencahayaan dengan mati nyala lampu ruangan yang dipasangkan sistem. Batasan rancangan system ini adalah program yang digunakan untuk mengontrol nyala dan mati lampu hanya bisa dikontrol menggunakan program yang dituliskan pada modul pemroses dan proses demonstrasi pada alat hanya melingkupi nyala lampu ketika ada siswa, mati lampu ketika ruangan kosong, dan tampilan web. Sistem yang dibuat terdiri dari hardware dan software. Hardware sistem akan menggunakan pemroses berupa mikroprosesor, dan sensor cahaya infra merah yang dipasang di pintu. Modul yang dirancang adalah modul program mikrokontroler, modul program tampilan web. Sedangkan modul yang tidak dirancang adalah modul mikrokontroler Arduino, modul sensor infrared, dan modul relay lampu. Sistem yang dirancang memiliki spesifikasi yaitu menggunakan sistem sensor inframerah untuk sensor keluar dan masuk pengunjung, menggunakan sebuah relay untuk kontrol nyala lampu, IOT digunakan untuk menampilkan status pengunjung ruangan pada website, dan hanya boleh terdapat 1 orang yang masuk atau keluar pada satu waktu.

Alat yang dirancang berfungsi untuk mengetahui jumlah orang yang keluar dan masuk suatu ruangan. Pemantauan dilakukan dengan melakukan pendeteksian menggunakan sensor inframerah yang terhubung ke mikrokontroller. Perhitungan dilakukan saat sensor mendeteksi adanya objek yang melewatinya. Data yang diperoleh mikrokontroller kemudian dikirim ke server menggunakan modul Wi-Fi sehingga perhitungan jumlah

\footnotetext{
${ }^{1}$ Program Studi Teknik Elektro, Universitas Tarumanagara,

2 Jurusan Teknik Elektro, Universitas Trisakti
} 
orang yang memasuki atau keluar dari suatu ruangan dapat dilakukan. Algoritma yang digunakan pada rancangan ini menggunakan algorima faulting untuk mengetahui kesalahan pembacaan pada sensor.

Data yang diterima pada server kemudian diberikan ke database untuk ditampilkan pada halaman web. Hasil yang ditampilkan pada halaman web berupa jumlah orang yang masuk dan keluar ruangan dan jumlah orang yang tersisa dalam ruangan tersebut. Nilai-nilai tersebut diambil dari database. Jumlah orang yang masuk dan keluar ruangan merupakan jumlah orang terhitung memasuki dan keluar dari ruangan tersebut, sementara jumlah orang tersisa dalam ruangan merupakan selisih dari jumlah orang yang memasuki dan keluar dari ruangan tersebut. Pemantauan jumlah orang yang memasuki, keluar dan tersisa dalam suatu ruangan dilakukan dengan menggunakan sensor fotodioda dan pemancar inframerah. Pemancar inframerah dan fotodioda diletakkan pada suatu tiang dan saling berhadapan. Setiap tiang terdapat 2 buah pemancar inframerah atau fotodioda. Sistem ini menggunakan 2 pasang tiang dan setiap pasang tiang memiliki 2 buah fotodioda dan pemancar inframerah. Tiap pasang tiang diletakkan pada pintu keluar dan masuk suatu ruangan untuk mendeteksi orang yang keluar dan masuk suatu ruangan. Sensor kemudian dihubungkan dengan mikrokontroller untuk dibaca nilainya. Mikrokontroller kemudian menentukan adanya orang yang memasuki ruangan atau tidak berdasarkan nilai dari sensor inframerah. Bentuk tiap pasang tiang diletakkan saling berhadapan seperti pada Gambar 1. Diagram blok dari rancangan sistem pemantauan jumlah orang pada suatu ruangan dapat dilihat pada Gambar 2.
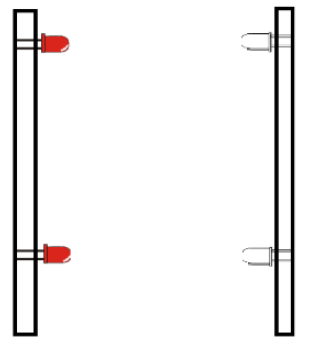

- Gambar 1. Bentuk Pemasangan Sensor

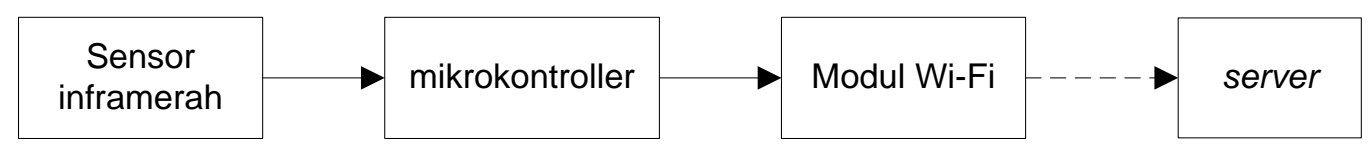

- Gambar 2. Diagram Blok Sistem

\section{KAJIAN PUSTAKA}

Internet of Things (IOT) merupakan suatu sistem perangkat komputasi, mesin mekanik, digital, hewan atau manusia yang saling terhubung yang memiliki tanda pengenal unik dan dapat melakukan pertukaran data tanpa interaksi antar manusia maupun antara manusia dengan komputer. IOT menunjuk ke perangkat fisik yang saling terhubung ke internet dan saling bertukar data. Dalam penggunaannya IOT banyak ditemui dalam berbagai aktifitas, contohnya : banyaknya transportasi online, e-commerce, pemesanan tiket secara online, live streaming, e-learning dan lain-lain bahkan sampai alat-alat untuk membantu dibidang tertentu seperti remote temperature sensor, GPS tracking, and sebagainya yang menggunakan internet atau jaringan sebagai media untuk melakukannya.

Wireless Fidelity (Wifi) merupakan teknologi Wireless Local Area Network (WLAN) yang distandarisasi dalam standar IEEE 802.11. Wifi digunakan untuk transmisi data secara wireless. Wifi dapat bekerja pada 2 frekuensi yang berbeda, yaitu pada frekuensi $2,4 \mathrm{GHz}$ dan $5,8 \mathrm{GHz}$. Wifi dengan frekuensi 2,4 $\mathrm{GHz}$ memiliki jangakauan jaringan yang lebih luas, tetapi memiliki tingkat gangguan yang tinggi bila dibandingkan dengan Wifi dengan frekuensi 5,8 GHz. Wi-Fi dengan frekuensi $2,4 \mathrm{GHz}$ memiliki tingkat gangguan yang lebih tinggi karena perangkat elektronik dan komunikasi lain banyak yang menggunakan frekuensi 2,4 GHz. Beberapa alat yang bekerja pada frekuensi $2,4 \mathrm{GHz}$ adalah microwave, komputer, dan juga jaringan telepon.

- Tabel 1 Spesifikasi Standar Wifi

\begin{tabular}{|c|c|c|c|}
\hline Standard & $\begin{array}{c}\text { Operating } \\
\text { Frequency }\end{array}$ & $\begin{array}{c}\text { Avaiable Bandwidth per } \\
\text { Channel }\end{array}$ & $\begin{array}{c}\text { Data Rate } \\
\text { (Max.) }\end{array}$ \\
\hline $802.11 \mathrm{a}$ & $\begin{array}{c}5,3 \mathrm{GHz} \text { and } 5,8 \\
\mathrm{GHz}\end{array}$ & $\sim 20$ to $22 \mathrm{MHz}$ & $54 \mathrm{Mbps}$ \\
\hline $802.11 \mathrm{~b}$ & $2,4 \mathrm{GHz}$ & $\sim 20$ to $22 \mathrm{MHz}$ & $11 \mathrm{Mbps}$ \\
\hline $802.11 \mathrm{~g}$ & $2.4 \mathrm{GHz}$ & $\sim 20$ to $22 \mathrm{MHz}$ & $54 \mathrm{Mbps}$ \\
\hline $802.11 \mathrm{n}$ & $\begin{array}{c}2.4 \mathrm{GHz} \text { or } 5 \\
\mathrm{GHz}\end{array}$ & 20 or $40 \mathrm{MHz}$ & $248 \mathrm{Mbps}$ \\
\hline
\end{tabular}


Mikrokontroler adalah suatu kontroler yang biasanya berbentuk Integrated Circuit. Mikrokontroler memiliki beberapa komponen pendukung, seperti memori, analog to digital (A/D) converter, digital to analog (D/A) converter, parallel I/O interface, serial I/O interface, timer dan counter. Diagram blok dari mikrokontroler dapat dilihat pada Gambar 3.

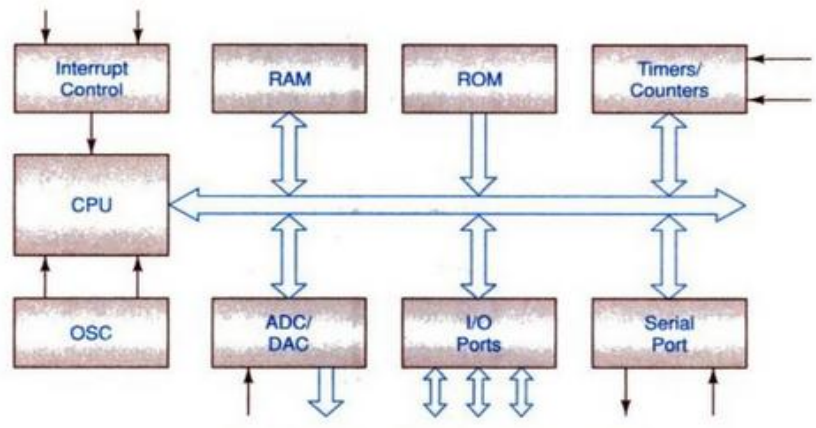

- Gambar 3 Diagram Blok Mikrokontroler

Mikrokontroler memiliki 2 tipe arsitektur yang masih digunakan sampai saat ini yaitu set instruksi yang kecil disebut Reduced Instruction Set Computer (RISC) machine dan mikrokontroler dengan set instruksi yang kompleks disebut Complex Instruction Set Computer (CISC) machine.

CISC memiliki banyak instruksi. Instruksi yang lebih banyak membantu programmer dalam menyediakan suatu program. Instruksi tersebut memiliki fungsi kerja yang kompleks, tetapi memudahkan programmer dalam membuat suatu program. RISC memungkinkan instruksi yang lebih sedikit, sederhana dan lebih cepat dibandingkan instruksi CISC yang lebih besar, kompleks dan lebih lambat.

\section{REALISASI RANCANGAN}

Mikrokontroler Arduino merupakan perangkat lunak dan perangkat keras yang digunakan untuk mengontrol sejumlah perangkat elektronik. Ada berbagai jenis Arduino, salah satunya adalah Arduino Mega. Arduino Mega 2560 adalah sebuah modul mikrokontroler berbasis ATmega 2560. Dalam proses memasukkan program ke Arduino, Arduino tidak memerlukan bantuan dari modul lain seperti downloader. Proses memasukan program ke Arduino cukup dengan menggunakan kabel serial yang sudah disediakan.

Arduino Mega 2560 memiliki 54 pin digital yang dapat digunakan menjadi input maupun output. Selain pin digital, modul ini juga mempunyai 16 pin analog. Pin analog juga dapat digunakan sebagai keluaran atau masukan sinyal digital. Modul ini juga memiliki 4 pasang pin serial atau yang sering disebut serial ports dan juga ICSP yang berguna untuk membuat koneksi dengan modul lain yang sesuai. Dengan adanya 4 pasang pin serial, Arduino Mega 2560 dapat melakukan komunikasi secara serial dengan beberapa modul pada suatu sistem yang sama. Arduino Mega 2560 ini membutuhkan tegangan kerja sebesar 5V dan memiliki port untuk memberikan tegangan 3,3V. Arduino Mega 2560 juga dapat menerima tegangan masuk sebesar 7-12V melalui power jack yang telah disediakan. Modul ini memiliki SRAM sebesar 8 KB dan EEPROM sebesar 4KB. Arduino Mega 2560 juga memiliki clock speed sebesar $16 \mathrm{MHz}$. Modul mikrokontroler Arduino Mega 2560 dapat dilihat pada Gambar 4.

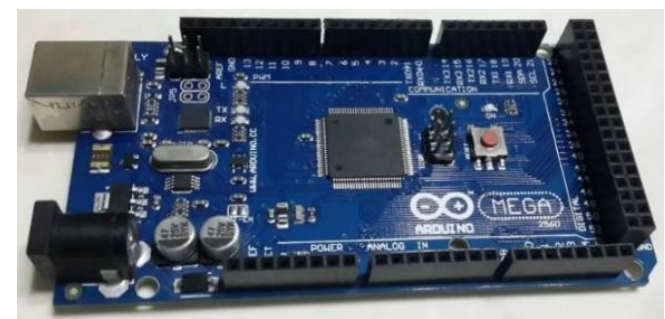

- Gambar 4. Modul Mikrokontroler Arduino Mega 2560

Apache merupakan web server yang menggunakan layanan Hyper Text Transfer Protocol (HTTP) untuk memberikan respon kepada pengguna berdasarkan permintaan yang dilakukan [7]. Fungsi utama Apache adalah untuk menangani komunikasi data melalui internet menggunakan protokol HTTP. Apache menyediakan berbagai layanan protokol melalui port yang berbeda yaitu HTTP melalui port 80, Simple Mail Transfer Protocol (SMTP) melalui port 25, Domain Name Service (DNS) untuk mengatur nama domain dengan IP address melalui port 25, dan File Transfer Protocol (FTP) untuk mengunggah dan mengunduh file melalui port 21. Web server Apache dapat diakses menggunakan Domain Name atau menggunakan IP address jika berada dalam satu jaringan lokal yang sama. Web server akan memberikan respon balik saat berupa teks, gambar, atau halaman web sesuai dengan permintaan, web server akan memberikan respon error jika sumber daya yang diminta tidak tersedia. 
Hypertext Preprocessor (PHP) adalah bahasa pemrograman web yang bersifat dinamis dan dapat digunakan pada Hyper Text Markup Languange (HTML). PHP merupakan server-side scripting dimana perintah dan instruksi pada php dieksekusi di server dan dan dikirim ke client dalam bentuk HTML. PHP disimpan dalam format American Standard Code for Information Interchange (ASCII) sebagai bahasa php dan dapat ditulis pada text editor pada berbagai sistem operasi. PHP juga mendukung berbagai basis data sehingga banyak digunakan untuk pengembangan web. Instruksi pada PHP dapat dieksekusi dengan cara mengakses web server kemudian respon balik akan dikirim ke client setelah PHP dieksekusi. Data yang dikirim dari mikrokontroller ke server berupa string dengan bentuk data yang sudah ditentukan, server kemudian mengolah data yang diterima dan melakukan pengecekan terhadap bentuk data. Data yang telah dicek kemudian diteruskan ke database untuk disimpan.

Sensor yang digunakan pada alat ini berupa sensor inframerah yang terdiri atas pemancar inframerah dan fotodioda. Dalam alat ini infra merah dan fotodioda berfungsi untuk mendeteksi orang yang masuk dan keluar pintu. Infra merah berfungsi sebagai pemberi gelombang untuk fototransistor. Infra merah merupakan sebuah gelombang elektromagnetik yang tidak dapat dilihat dengan kasat mata manusia. Gelombang infra merah ini memiliki panjang gelombang yang lebih panjang dari gelombang cahaya biasa yaitu sekitar 800-1000 nanometer. Gelombang infra merah memiliki beberapa karakteristik antara lain gelombang infra merah tidak dapat dilihat dengan kasat mata, gelombang infra merah tidak dapat menembus benda yang tidak tembuh pandang, dan dapat ditimbulkan oleh benda yang dapat menghasilkan panas. Gelombang infra merah ini memiliki banyak kegunaan di beberapa bidang antara lain dalam bidang kesehatan, bidang komunikasi, dan bidang industri. Gelombang infra merah dapat dihasilkan oleh sebuah pemancar infra merah.

Fotodioda merupakan sebuah komponen semikonduktor yang dapat menghasilkan arus listrik yang saat terdapat cahaya yang mengenainya. Selain memghasilkan arus listrik, fotodioda juga dapat dialiri arus secara eksternal saat dihubungkan dengan sumber tegangan. Besar arus yang dapat melewati fotodioda bergantung pada banyaknya cahaya yang diberikan. Arus yang melewati fotodioda semakin besar saat intensitas cahaya inframerah yang diberikan semakin besar dan berlaku sebaliknya. Fotodioda yang digunakan pada perancangan ini adalah fotodioda untuk mendeteksi cahaya inframerah.

Perangkat lunak phpMyAdmin berfungsi untuk manajemen basis data yang ter-install pada Raspberry Pi 3 model B. PhpMyAdmin merupakan perangkat lunak web berbasis PHP open-source yang digunakan sebagai alat untuk mengolah basis data MySQL. MySQL merupakan implementasi dari sistem manajemen berbasis data relasional yang medukung adanya hubungan antar tabel. MySQL juga dikategorikan sebagai server basis data yang open-source dengan lisensi GNU General Public License (GPL). Aplikasi web phpMyAdmin juga menyediakan fitur yang terdapat pada MySQL seperti pembuatan basis data, pembuatan tabel, dan akun pengguna yang dapat diatur hak penggunaannya. PhpMyAdmin menyediakan Graphical User Interface (GUI) yang memudahkan pengguna untuk membuat, mengedit, dan mengatur basis data. Tampilan awal phpMyAdmin dapat dilihat pada Gambar 5.

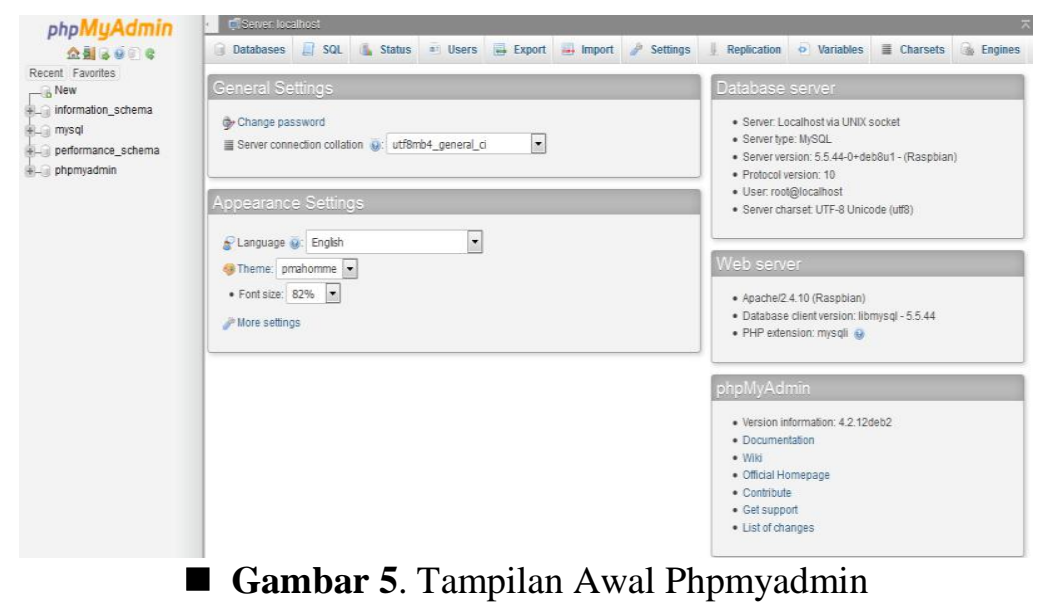

MySQL menggunakan Bahasa Structured Query Language (SQL) yang merupakan konsep dalam melakukan operasi basis data, terutama dalam seleksi dan pemasukan data agar setiap operasi data dilakukan secara otomatis dengan mudah. Fungsi utama MySQL adalah sebagai tempat penyimpanan data (basis data) berbasis web server. Basis data dapat diartikan sebagai kumpulan data yang tersusun secara sistematis yang memudahkan pengguna untuk mengakses dan mengatur data sehingga pengguna dapat mengambil informasi dengan mudah. MySQL memiliki sistem basis data yang relasional di mana data disimpan dalam bentuk tabeltabel yang terpisah sehingga data yang disimpan terstruktur dan terorganisir. 
ESP8266 adalah sebuah chip yang sudah lengkap dimana didalamnya sudah termasuk processor, memori dan juga akses ke GPIO. Hal ini menyebabkan ESP8266 dapat secara langsung menggantikan Arduino dan memiliki fitur untuk terhubung ke Wifii secara langsung.

IoT semakin berkembang seiring dengan bejalannya waktu, modul yang berbasiskan Ethernet maupun wifi semakin banyak dan beragam dimulai dari Wiznet, Ethernet shield hingga yang terbaru adalah Wifi module yang dikenal dengan ESP8266. Ada beberapa jenis ESP8266 yang dapat ditemui dipasaran, namun yang paling mudah didapatkan di Indonesia adalah type ESP-01,07,dan 12 dengan fungsi yang sama perbedaannya terletak pada GPIO pin yang disediakan.

Modul sensor inframerah digunakan untuk mendeteksi adanya orang yang memasuki atau keluar dari suatu ruangan. Modul ini terdiri atas 4 pasang fotodioda dan pemancar inframerah, tiap pasang pemancar inframerah dan fotodioda diletakkan saling berhadapan. Modul ini terbagi menjadi sensor inframerah masuk dan keluar. Sensor inframerah masuk menggunakan 2 pasang pemancar inframerah dan fotodioda yang diletakkan di dalam pintu, sementara sensor inframerah keluar menggunakan 2 pasang pemancar inframerah dan fotodioda yang diletakkan di dalam ruangan. Apabila terdapat orang yang memasuki ruangan, maka nilai yang diberikan sensor inframerah masuk bernilai besar. Apabila terdapat orang yang keluar dari ruangan, sensor inframerah keluar akan bernilai besar. Rangkaian modul sensor inframerah dapat dilihat pada Gambar 6.

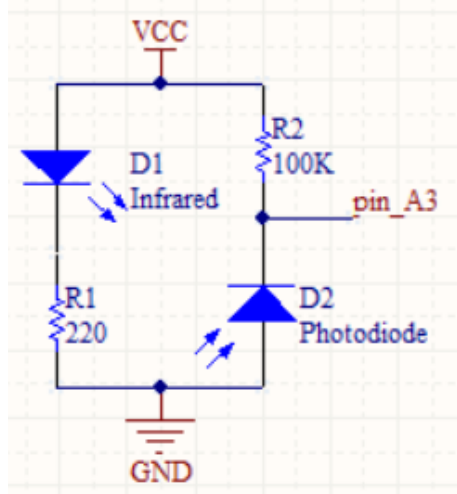

- Gambar 6. Rangkaian Modul Sensor Inframerah

Modul penghubung ke database digunakan untuk mengirimkan data dari mikrokontroller ke server lalu diteruskan ke database. Modul ini menggunakan ESP8266 untuk terhubung ke server. ESP8266 yang digunakan merupakan versi 1.0. ESP8266 memiliki 8 buah pin yaitu pin VCC dihubungkan ke tegangan 3.3 V, GND dihubungkan ke ground, RST sebagai pin reset tidak digunakan, GPIO 0 dan GPIO tidak digunakan, Rx dihubungkan dengan rangkaian voltage divider $1 \mathrm{k} \Omega$ dan $2 \mathrm{k} \Omega$ ke pin Tx mikrokontroller, Tx dihubungkan ke pin Rx mikrokontroller, dan pin CH sebagai pin enable dihubungkan dengan resistor pull-up $10 \mathrm{k} \Omega \mathrm{ke}$ pin VCC. Rangkaian modul penghubung ke database dapat dilihat pada Gambar 7.

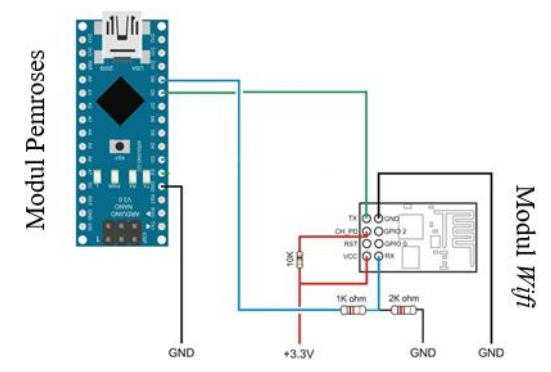

- Gambar 7. Rangkaian Modul ESP8266

Program pemroses di mikrokontroler berfungsi untuk mengatur modul penghubung ke database dan meengolah nilai yang diterima dari modul sensor inframerah. Modul pemroses mulanya menghubungkan modul ESP8266 dengan koneksi Internet yang sudah ditentukan. Apabila koneksi gagal, modul pemroses akan melakukan hubungan ulang ke server. Modul pemroses kemudian melakukan pembacaan nilai dari modul sensor inframerah. Nilai yang diterima modul pemroses selanjutnya diproses untuk menentukan adanya orang yang memasuki atau keluar dari ruangan. Modul pemroses kemudian mengirimkan hasil yang didapat ke server lalu diteruskan ke database. Diagram alir modul program pemroses pada mikrokontroller dapat dilihat pada Gambar 8.

Modul database yang dirancang memiliki fungsi sebagai media penyimpanan data yang terdapat pada komputer. Data yang perlu disimpan pada database adalah jumlah orang yang memasuki dan keluar dari ruangan. Data tersebut dikirimkan oleh modul pemroses melalui internet menggunakan modul penghubung ke database. 
Database yang digunakan adalah MySQL. Database yang digunakan memiliki jumlah tabel sebanyak 1 buah tabel. Data yang terdapat pada database selanjutnya digunakan untuk ditampilkan pada halaman web.

\section{HASIL PENGUJIAN DAN ANALISIS}

Pengujian modul sensor inframerah bertujuan untuk mengetahui nilai yang diberikan sensor. Pengujian modul sensor inframerah dilakukan dengan mengamati nilai analog dari fotodioda dan tegangan pada fotodioda saat terdapat orang yang melewati modul sensor inframerah. Pengujian untuk nilai analog dan tegangan pada fotodioda dilakukan sebanyak 5 kali. Hasil pengujian modul sensor inframerah berdasarkan nilai analog fotodioda dapat dilihat pada Tabel 2.

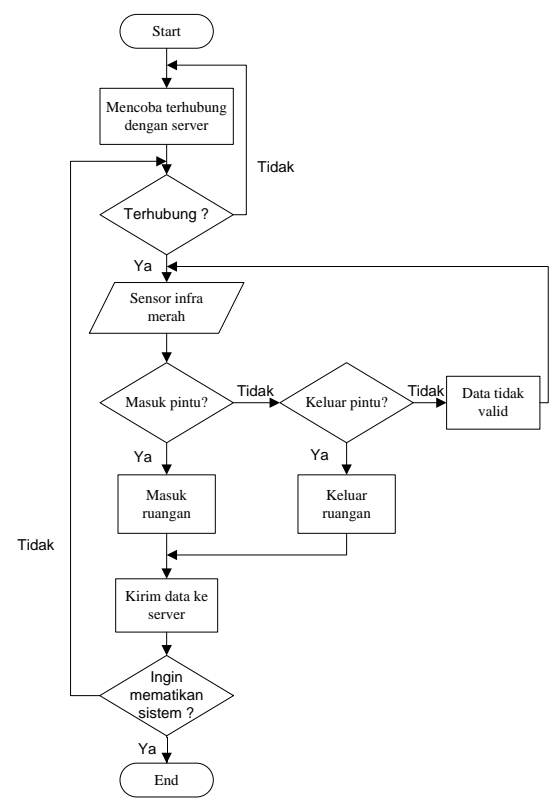

ש Gambar 8. Diagram Alir Modul Program Pemroses pada Mikrokontroller

- Tabel 2. Tabel Pengujian Modul Sensor Inframerah

\begin{tabular}{|c|c|c|c|c|c|c|c|c|}
\hline \multirow{2}{*}{ No } & \multicolumn{4}{|c|}{ Nilai analog saat terdapat orang } & \multicolumn{4}{|c|}{ Nilai analog saat tidak terdapat orang } \\
\cline { 2 - 9 } & P1 & P2 & P3 & P4 & P1 & P2 & P3 & P4 \\
\hline 1 & 958 & 944 & 963 & 969 & 689 & 692 & 784 & 776 \\
\hline 2 & 946 & 950 & 968 & 964 & 683 & 689 & 788 & 772 \\
\hline 3 & 953 & 946 & 965 & 961 & 686 & 683 & 780 & 779 \\
\hline 4 & 960 & 948 & 970 & 972 & 691 & 695 & 779 & 780 \\
\hline 5 & 949 & 941 & 959 & 964 & 690 & 696 & 785 & 775 \\
\hline
\end{tabular}

Pengujian modul sensor inframerah berdasarkan nilai analog fotodioda dilakukan dengan mengambil nilai analog yang terbaca melalui pin analog mikrokontroller Arduino mega 2560. Hasil pengujian modul sensor pupuk berdasarkan nilai analog fotodioda menunjukkan bahwa nilai analog dari fotodioda saat tedapat orang berada di atas 900 dan saat tidak terdapat orang berada di bawah 800 . Hasil pengujian yang dilakukan sebanyak 5 kali memperlihatan setiap pengukuran memberikan hasil yang tidak jauh berbeda. Berdasarkan hasil pengujian dapat dikemukakan bahwa semakin kecil intensitas cahaya yang diberikan ke fotodioda resistansi pada fotodioda semakin besar dan semakin besar intensitas cahaya yang diberikan ke fotodioda resistansi pada fotodioda semakin kecil.

Pengujian modul pengubung ke database dilakukan untuk memastikan bahwa modul pemroses dapat terhubung ke server dengan baik. Pengujian modul ini dilakukan dengan mengamati hasil pengecekan hubungan saat modul pemroses berusaha terhubung ke server. Hasil pengeckan oleh modul pemroses ditampilkan pada layar monitor. Modul pemroses akan mengembalikan nilai "TCP connected" saat hubungan berhasil dan nilai "TCP not connected" bila hubungan gagal. Hasil pengujian modul penghubung ke database dapat dilihat pada Tabel 3.

- Tabel 3. Hasil Pengujian Modul Penghubung ke Database

\begin{tabular}{|c|c|}
\hline Pengujian ke- & Hasil \\
\hline 1 & TCP connected \\
\hline 2 & TCP connected \\
\hline 3 & TCP connected \\
\hline
\end{tabular}


Pengujian modul ini dilakukan sebanyak 3 kali. Berdasarkan hasil pengujian yang dilakukan 3 kali, modul penghubung ke database berhasil melakukan hubungan ke database. Dengan demikian dapat dikemukakan bahwa modul penghubung ke database dapat menghubungkan ke server dengan baik.

Pengujian modul database dilakukakn untuk mengetahui data yang diterima database sama seperti data yang dikirim modul pemroses. data yang dikirim berupa data string dengan format tertentu. Data ini kemudian diolah server dan diteruskan ke database. Pengujian dilakukan dengan membandingkan data yang dikirim modul pemroses dan data yang diterima pada database. Pengujian dilakukan sebanyak 3 kali. Hasil pengujian modul database dapat dilihat pada Tabel 4

Tabel 4. Hasil Pengujian Modul Database

\begin{tabular}{|c|c|c|c|c|}
\hline \multirow{2}{*}{ Pengujian ke- } & \multicolumn{2}{|c|}{ Data dari modul pemroses } & \multicolumn{2}{c|}{ Data pada database } \\
\cline { 2 - 5 } & masuk & keluar & masuk & keluar \\
\hline 1 & 1 & 0 & 1 & 0 \\
\hline 2 & 0 & 1 & 1 & 1 \\
\hline 3 & 1 & 0 & 2 & 1 \\
\hline
\end{tabular}

Tabel 4 memperlihatkan bahwa nilai yang terdapat pada database merupakan nilai yang ditambahkan dengan data dari modul pemroses. berdasarkan hasil pengujian yang dilakukan 3 kali, dapat dikemukakan bahwa modul database dapat menyimpan data yang dikirim oleh modul pemroses. Gambar 9 adalah sistem yang telah diuji coba dalam ruangan uji yaitu berupa ruangan kelas dalam ukuran yang lebih kecil.

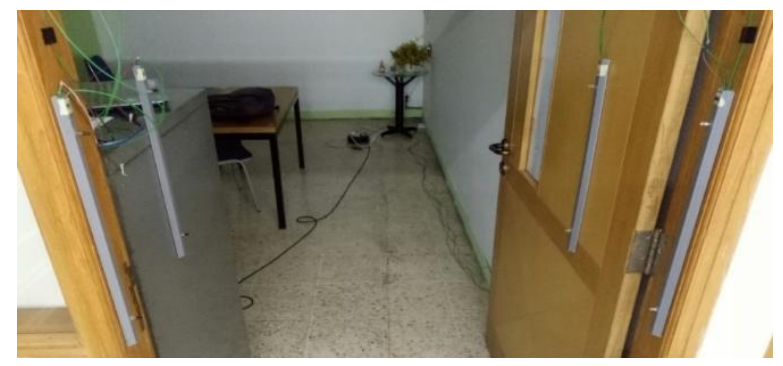

- Gambar 9 Hasil rancangan sistem yang diimplementasikan dalam ruangan uji

\section{KESIMPULAN DAN SARAN}

Kesimpulan yang diperoleh dari perancangan sistem ini adalah sistem menggunakan internet dapat digunakan untuk memantau jumlah orang dalam ruangan, sistem ini dapat mematikan dan menyalakan lampu saat terdapat orang dalam ruangan, dan sistem ini dapat memberitahu jumlah orang yang memasuki dan keluar dari ruangan. Pengembangan lebih lanjut sistem ini dapat dilakukan dengan menggunakan sensor yang lebih baik, dikarenakan sensor inframerah yang digunakan tidak memberikan performa yang baik jika dipisah dalam jarak yang jauh dan adanya cahaya matahari yang kuat. Server yang digunakan dapat diganti dengan server yang memiliki performa yang lebih baik, dikarenakan server yang digunakan saat ini hanya mampu mengeksekusi satu request pada saat yang sama.

\section{DAFTAR PUSTAKA}

[1] B. Mukhlis, Penghematan Energi Melalui Penggantian Lampu Penerangan Di Lingkungan UNTAD, Jurnal Ilmiah Foristek, Vol. 1, No. 2, September 2011.

[2] J. G. Brookshear, Computer Science: Suatu Pengantar, edisi 7, Jakarta: Penerbit Erlangga, 2003.

[3] M. Flynn dan S. Oberman, Advanced Computer Arithmetic Design, New York: Wiley, 2001.

[4] B. W. Lampson, Hints for Computer System Design, Operating Systems Reviews, No. 15, 1983, p. 33-48.

[5] A. Winoto, Mikrokontroler AVR Atmega8/32/16/8535 Bahasa C pada WinAVR, Bandung: Penerbit Informatika, 2008.

[6] G. Myklebust, The AVR Microcontroller and C Compiler Co-Design, Trondheim, Norway: ATMEL Development Center.

\section{UCAPAN TERIMAKASIH, KEPADA:}

- Kemenristek Dikti, atas bantuan dana hibah guna pelaksanaan PKM 2018

- PT Honoris Indonesia (PT Hori), atas bantuan pengadaan lampu TL-LED, sebagai bagian CSR perusahaan.

- DPPM Universitas Tarumanagara, atas bantuan dana pendampingan guna memperlancar kegiatan PKM ini. 